\title{
Improving clinical care through the stories we tell
}

\author{
Narrative Psychiatry: How Stories Can \\ Shape Clinical Practice \\ Bradley Lewis \\ Johns Hopkins University Press; 2011.
}

I $\mathrm{f}$ there is any specialty that should be receptive to the proposition that stories can extend the limits of conventional medicine, it is psychiatry. The work of psychiatrists is inextricably tied to the stories our patients tell us, whether we are listening for diagnostic or therapeutic purposes. The inherent complexity of psychiatric conditions calls for a nuanced approach that is flexible enough to accommodate multiple interpretations of the plots, characters and metaphors that present themselves in the clinical setting. Until the day when we diagnose depression with a brain scan or social phobia with a blood test (a day that will surely never come), psychiatry will remain intertwined with narrative.

But if this is the case, why has psychiatry not been more influential within the developing field of narrative medicine? This is one of the questions posed by Dr. Bradley Lewis in this book. Lewis, a psychiatrist and professor of medical humanities and cultural studies at New York University, has previously written books on psychiatry and postmodern philosophy. In Narrative Psychiatry, he argues that efforts to be rigorously scientific and biological have "cut psychiatry off from important humanistic trends in both medicine and psychotherapy" so that we have reached a point when, paradoxically, the rest of medicine is "more open than psychiatry to the human and the storied aspects of clinical work."

The rise of biopsychiatry has been one of the most significant and controversial developments in the short his-

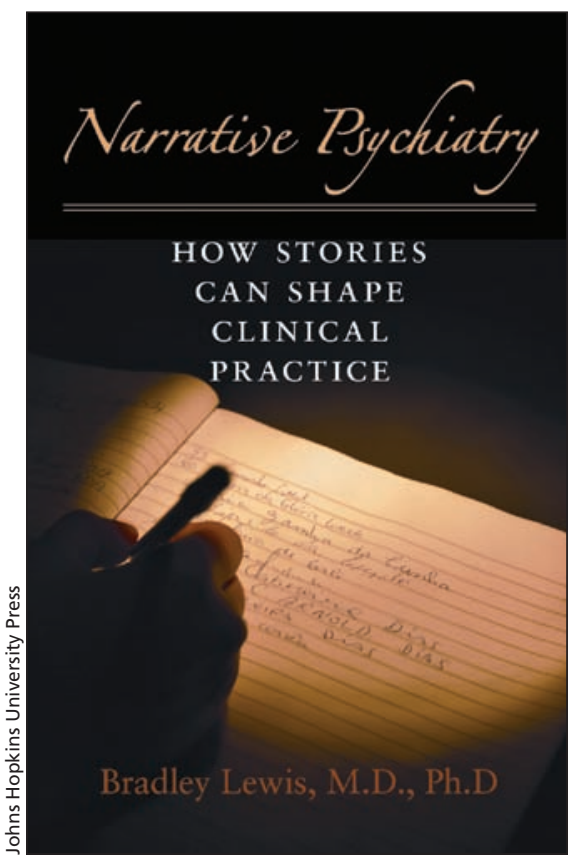

tory of psychiatry as a specialty. Often those who criticize biopsychiatry and its connection to the pharmaceutical industry take an antipsychiatry stance. However, Lewis is not one of these. Nor does he restrict himself to purely philosophical considerations such as defining narrative psychiatry. Rather, he takes a clinically oriented approach to the question of how psychiatrists can incorporate the insights of narrative medicine and narrative therapy into their practice, one that does not reject the need for biological treatments when appropriate.

A considerable portion of the book is devoted to a detailed analysis of a work of short fiction. Over several chapters, Lewis describes how psychiatrists from different theoretical orientations might formulate the difficulties faced by one of the fictional characters. The purpose is to demonstrate the varied conceptions of the case that are possible; one of the key tenets of narrative theory is that there is not a sole "truth" to be "discovered," but many possible ways of understanding that each have advantages and disadvantages. The role of the practitioner is to remain curious, tolerant of ambiguity and open to whatever approach the patient will ultimately find most congruent and helpful.

This book provides a good summary of the major philosophical shifts in psychiatry, as well as an overview of both narrative medicine and narrative therapy. The use of short fiction to illustrate how different forms of psychotherapy might approach the same case is clear and engaging, and would be a useful teaching resource for psychiatry residents or others learning about schools of psychotherapy for the first time. However, it may not have been necessary for Lewis to spend quite so much time describing multiple therapies for readers to grasp the basic idea that many different interpretations of the same case are possible. Instead, additional examples of narrative psychiatry in practice might have been useful. There is only a single chapter at the end of the book on "Doing narrative psychiatry," leaving the reader who wishes to change his or her practice without much to go on.

If Lewis is correct, then the growing strength of narrative within psychiatry will reduce the tensions within the specialty that arose from an over-reliance on biological models. Narrative Psychiatry is a well-written, timely and engaging book that will appeal to psychiatrists and any others who are interested in how narrative approaches might improve the care we provide to patients.

\section{Lara Hazelton MD}

Psychiatrist

Halifax, NS

CMAJ 2012. DOI:10.1503/cmaj.111341 